\title{
Ligand Effects in Pd-Catalyzed Intermolecular Alkyne Hydroarylations
}

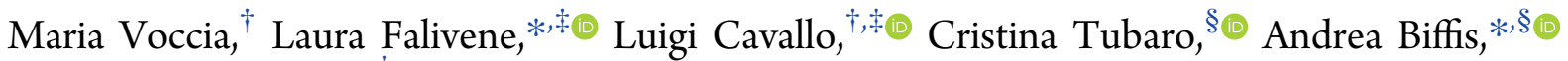 \\ and Lucia Caporaso ${ }^{*}, \dagger$ \\ ${ }^{\dagger}$ Department of Chemistry, University of Salerno, Via Ponte Don Melillo, 84084-Fisciano, SA, Italy \\ ${ }^{\ddagger}$ King Abdullah University of Science and Technology, Chemical and Life Sciences and Engineering, Kaust Catalysis Center, Thuwal \\ 23955-6900, Saudi Arabia \\ ${ }^{\S}$ Dipartimento di Scienze Chimiche, Università di Padova, via Marzolo 1, Padova 35131, Italy
}

\section{Supporting Information}

ABSTRACT: The use of palladium(II) catalysts for the synthesis of aryl alkenes by addition of aromatic $\mathrm{C}-\mathrm{H}$ bonds to alkynes has received a great interest in the literature. The mechanistic features of the reaction have been largely discussed, but no systematic study has been reported so far, particularly for what concerns the role of ligands. In this work, we performed a detailed theoretical study in order to fill this gap. To this extent, three different systems have been considered, with the aim to emphasize how the steric and electronic metal environment affects the catalytic activity and, most notably, steers the reaction selectivity toward the two main products of single and double alkyne insertion into the aromatic $\mathrm{C}-\mathrm{H}$ bond. Moreover, given the crucial role of the

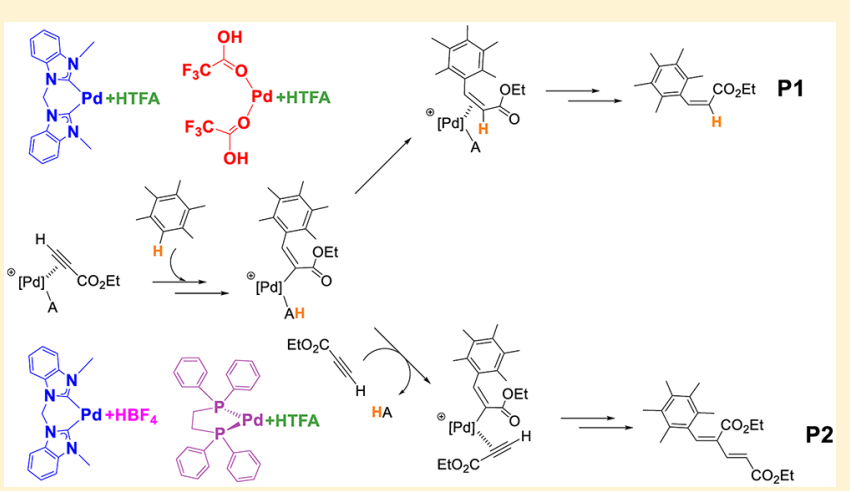
acid media, two acids have been considered, namely, trifluoroacetic acid and tetrafluoroboric acid, to understand the effect of the acid strength and coordinative power on the competition between the different pathways.

\section{INTRODUCTION}

The addition of an aromatic $\mathrm{C}-\mathrm{H}$ bond to the triple bond of an alkyne is a very practical route for the introduction of alkenyl groups into aromatic compounds. ${ }^{1-4}$ Such a reaction, commonly termed "hydroarylation", 5 presents indeed several advantages, such as perfect atom economy and potentially high chemo-, regio-, and stereoselectivity. For example, the regioselectivity of the $\mathrm{C}-\mathrm{H}$ addition depends primarily on the electronic properties of the substituents at the alkyne, particularly in the case of terminal alkynes: electron-donating as well as aromatic substituents promote the formation of a Markovnikov addition product, whereas anti-Markovnikov selectivity is generally recorded in the presence of electronwithdrawing substituents. $^{1-4}$ The stereoselectivity of the reaction is also remarkable: in the majority of cases, formal trans-addition of the $\mathrm{C}-\mathrm{H}$ bond to the alkyne is observed, which, in the case of electron-poor terminal alkynes, typically yields Z-1,2-disubstituted olefins, i.e., the less thermodynamically stable stereoisomer. As consequence, in this context, the hydroarylation reaction efficiently complements more traditional cross-coupling methodologies for the preparation of 1,2disubstituted olefins, most notably the Heck reaction, ${ }^{6}$ which generally yields the more stable $E$ isomer as product. Finally, the chemoselectivity of the reaction can vary as well, from standard single hydroarylation products (type 1, Scheme 1) to
Scheme 1. Potential Chemoselectivity of a Hydroarylation Reaction $^{7-9}$

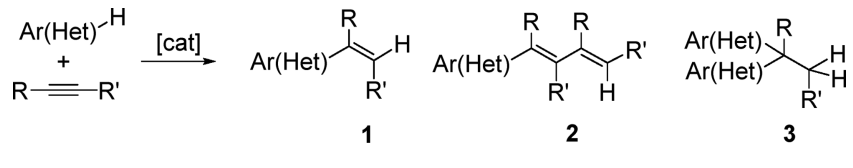

products of multiple alkyne insertion into the same $\mathrm{C}-\mathrm{H}$ bond (type 2$)^{7,8}$ or of multiple hydroarylation of the same triple bond (type 3 ) ${ }^{9}$ the last one generally arises only with the most electrophilic arenes and heteroarenes.

Both the regio- and stereoselectivity of the reaction are influenced by the actual occurring mechanism. This, in turn, depends on the catalyst that is employed, whose role is mainly to convert either the arene or the alkyne into a more nucleophilic/electrophilic species, thus lowering the activation barrier for the reaction. The two possible mechanisms (Scheme 2) have been largely discussed in the literature, ${ }^{10,11}$ and they differ not only in the activation step but also in the stereochemical consequences. For example, when the reaction proceeds in a Friedel-Crafts fashion (Scheme 2, at the top), the catalyst, possessing soft Lewis acid character, coordinates

Received: July 11, 2019 
Scheme 2. Possible Reaction Mechanisms Proposed for the Direct Alkyne Hydroarylation Reaction: Friedel-Crafts (at the Top) and Arene Metalation (at the Bottom) ${ }^{3,27}$
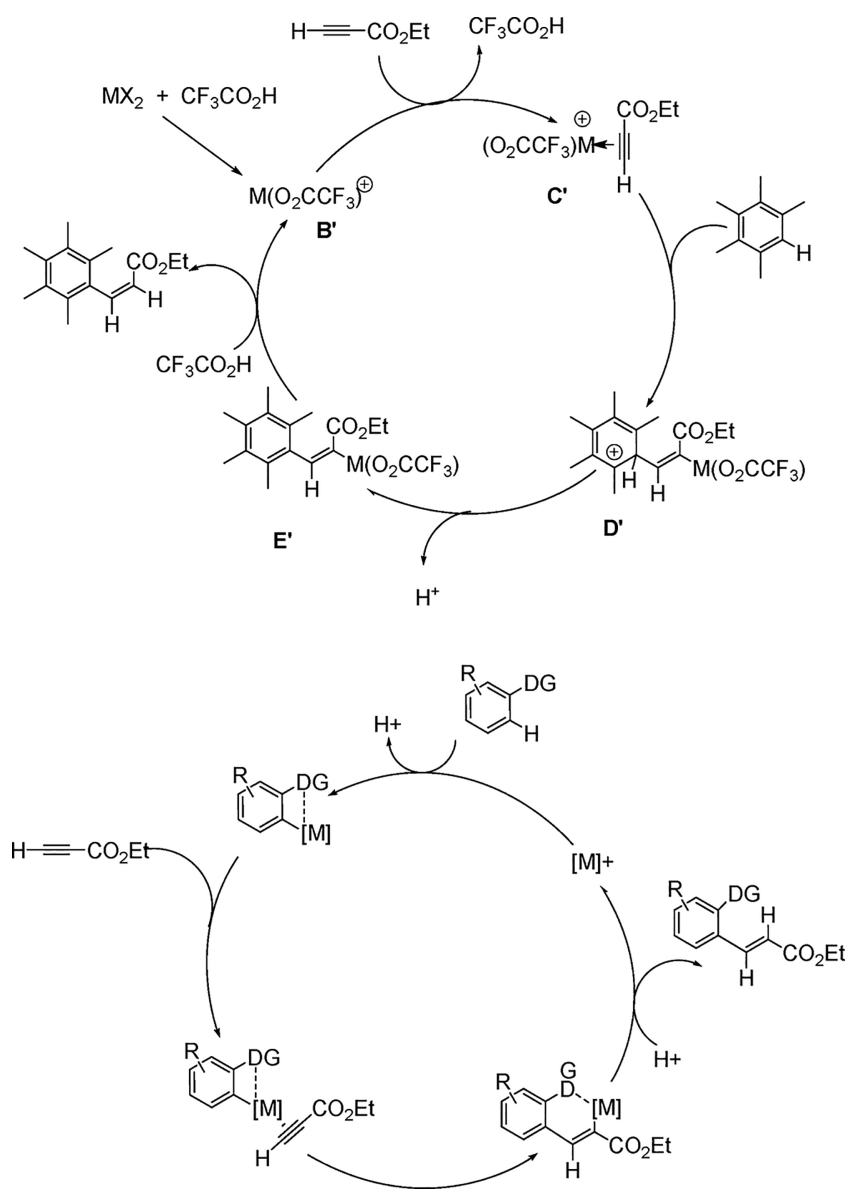

the alkyne, which attacks the arene, forming a Wheland-type intermediate (in anti fashion); upon subsequent proton dissociation and protonolysis of the metal-vinyl bond, this intermediate liberates the $Z$ product and the catalyst for another reaction cycle. A variant of this mechanism concerns terminal alkynes or alkynes functionalized with a leaving group at one end (halide, carboxylate...), which might isomerize to vinylidenes in the metal coordination sphere prior to electrophilic attack on the arene. However, the incidence of this mechanistic variant in the case of alkyne hydroarylation reactions is rather low, and it has been validated mostly in the case of intramolecular hydroarylation reactions, and particularly when metal centers prone to vinylidene formation (e.g., ruthenium) are used as catalysts. ${ }^{12}$ Alternatively, the catalyst can first metalate the arene and subsequently insert the alkyne into the metal-aryl bond (in syn fashion); subsequent protonolysis of the intermediate regenerates the catalyst and produces the reaction product as the $E$ stereoisomer (Scheme 2 , at the bottom). This second possibility is generally limited to arenes featuring directing groups (which can precoordinate to the catalyst directing and promoting its attack to a specific position of the arene), ${ }^{13,14}$ or to intramolecular reactions (in which the alkyne tethered to the arene may itself act as a directing group and insert in a second moment into the metalaryl bond). ${ }^{15}$

Less electrophilic metal centers generally prefer the arene metalation route, ${ }^{16-19}$ which, however, is less straightforward (requires prior installation of the directing group or the synthesis of the arene-alkyne adduct) and also less efficient (requires higher temperatures to reach a satisfactory reaction rate). On the other hand, more electrophilic metal centers such as late transition metals in medium to high oxidation states, early transition metals, rare earths, and main group elements of the $\mathrm{p}$ block, do promote the Friedel-Crafts route. ${ }^{20-24}$ Interestingly, $\mathrm{Pd}(\mathrm{II})$ has been reported to exploit both reaction mechanisms, depending on the substrates and the reaction conditions. $^{15,25-31}$ Thanks to this flexibility and to the great efficiency in promoting the reaction, $\mathrm{Pd}$ (II) is undoubtedly the metal center that, up to now, has been most commonly employed as catalyst for intermolecular alkyne hydroarylation reactions.

The first investigation on the mechanism of action of palladium centers was provided by the group of Fujiwara in their pioneering work on cationic Pd(II) species formed in situ under acid conditions in the intermolecular alkyne hydroarylation reaction with unfunctionalized substrates. ${ }^{25,26}$ On one hand, Fujiwara detected a vinylpalladium species as crucial intermediate of the reaction, but, on the other hand, he postulated a mechanism based on arene metalation (Scheme 2, at the bottom) based on experimental data that could be equivocal. Indeed, this proposal was shortly thereafter disputed by Tunge and Foresee, ${ }^{27}$ who performed a thorough mechanistic study based on the kinetic isotope effect for an intramolecular hydroarylation reaction. They found the reaction mechanism based on alkyne $\pi$-activation (without isomerization to vinylidene species) much more compatible with their experimental data, and they proposed the final protonolysis step as the rate-determining step of the reaction. This result was further corroborated by theoretical investigation by Soriano and Marco-Contelles ${ }^{28}$ and Strassner, ${ }^{29}$ and, more recently, by mass spectroscopic investigation on the reaction intermediates by the group of Correia. ${ }^{30}$ Only recently, an arene metalation route was again proposed for an intermolecular Pd-catalyzed alkyne hydroarylation reaction under acid conditions, ${ }^{31}$ but the DFT calculations performed to support the mechanistic proposal could not locate all the key intermediates.

While the essential features of the mechanism seem quite well established by these studies, the role of the ancillary ligands coordinated to $\mathrm{Pd}(\mathrm{II})$ has received very scarce attention up to now. Actually, this role appears crucial for many aspects. For example, chelating di-N-heterocyclic carbene (NHCs) ligands significantly increase the reactivity of $\mathrm{Pd}(\mathrm{II})$ in the reaction. ${ }^{34}$ Furthermore, modifying the ligand allows to steering the reaction selectivity, for example, toward the formation of products of formal double alkyne insertion into the arene $\mathrm{C}-\mathrm{H}$ bond. ${ }^{7}$ In this study, we aim at filling this gap and at rationalizing the active role of the ligand as well as of the acid by a theoretical approach.

\section{RESULTS AND DISCUSSION}

A comprehensive theoretical DFT study of the hydroarylation of ethyl propiolate (S1) via $\mathrm{C}-\mathrm{H}$ activation of pentamethylbenzene (S2) has been performed (Figure 1). To have a detailed understanding of the mechanistic aspects and of the impact of the metal ancillary ligands on the reaction rate and on the selectivity, we investigated the behavior of three palladium(II) catalysts (Figure 1), namely, $\mathrm{Pd}(\mathrm{OAc})_{2}(\mathrm{OAc}=$ acetate, Fujiwara catalyst $\mathbf{1 A}),(\mathrm{di}-\mathrm{NHC}) \mathrm{PdX}_{2}(\mathrm{X}=$ halide and $\mathrm{NHC}=$ methylenebis $(N$-methylbenzimidazolin-2-ylidene $)$, 


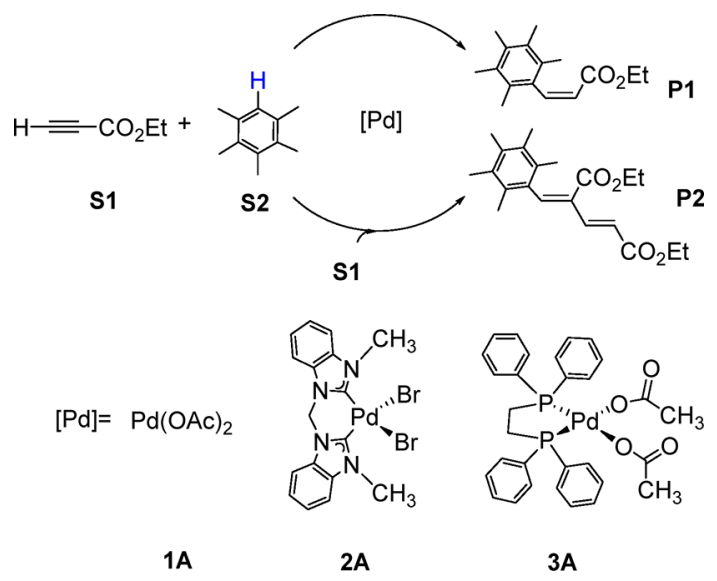

Figure 1. Schematic structures of the investigated reaction and of the employed catalysts.

Biffis catalyst 2A), and (dppe)Pd(OAc) $)_{2}($ dppe $=1,2-$ bis(diphenylphosphino)ethane, Kitamura catalyst 3A). Moreover, since the experimental conditions require the presence of an excess of acid in the environment, we modeled the reaction in the presence of trifluoroacetic acid (HTFA) and tetrafluoroboric acid $\left(\mathrm{HBF}_{4}\right)$ in order to rationalize also the effect of the acid nature on the obtained products.

All energies reported are Gibbs free energies ( $\mathrm{kcal} / \mathrm{mol}$ ) evaluated at $298.15 \mathrm{~K}$ and $1.0 \mathrm{~atm}$ in $\mathrm{CH}_{2} \mathrm{Cl}_{2}$ as solvent. The presence of HTFA/TFA ( or $\mathrm{HBF}_{4} / \mathrm{BF}_{4}$ ) in the reaction media was considered in agreement with the experimental conditions used for the reported reactions of pentamethylbenzene with ethyl propiolate (mixed solvent TFA/ $\mathrm{CH}_{2} \mathrm{Cl}_{2}, 4 / 1$ by volume, at $\left.25^{\circ} \mathrm{C}\right) \cdot{ }^{3,7,25}$

Catalytically Active Species and Ethyl Propiolate (S1) Coordination. At first, we focused on the formation of the catalytically active species. For all the three catalysts, the active species consists in the cationic square planar complex $\mathbf{B}$ in which Pd coordinates one molecule of trifluoroacetate (TFA) and one molecule of HTFA in addition to the ancillary ligands of the precatalysts, i.e., two molecules of HTFA, the di-NHC, and the DPPE for 1A, 2A, and 3A, respectively; see Figure 2. The two OAc ligands coordinated initially to $\mathrm{Pd}$ in $\mathbf{1 A}$ and $\mathbf{3 A}$ are promptly replaced by $(\mathrm{H}) \mathrm{TFA}$ in the reaction mixture. ${ }^{32}$ Similarly, the two halides in $\mathbf{2 A}$ are also replaced by $(\mathrm{H}) \mathrm{TFA}$ as shown by the DFT calculations reported by Strassner et al., ${ }^{33}$ and also for the almost identical catalytic performance recorded for systems with the same di-NHC ligand and different halides. ${ }^{34}$ In all cases, complexes $\mathbf{B}$ show a stabilizing hydrogen interaction between the TFA and the HTFA.

Starting from B, S1 coordinates to the metal by replacing the HTFA molecule. For this step we explored both the one-step $(\mathbf{B} \rightarrow \mathbf{C})$ and the stepwise $(\mathbf{B} \rightarrow \mathbf{B 2} \rightarrow \mathbf{C})$ mechanism; see Figure 2.

The one-step pathway consists in a simultaneous decoordination of HTFA and $\eta^{2}$ coordination of S1 to the Pd in the position cis to $\mathrm{TFA}^{35}$ In the transition state, the complex assumes a trigonal bipyramid geometry with S1 and HTFA lying in the equatorial plane (the alternative square pyramidal TS is calculated higher in energy). The energy barrier for this step is $12.6,13.7$, and $7.4 \mathrm{kcal} / \mathrm{mol}$ for $\mathbf{1 A}, \mathbf{2 A}$ and $\mathbf{3 A}$, respectively. Such a lower energy barrier for $3 \mathrm{~A}$ is ascribed to the lower positive charge on Pd (see Table S1) that weakens the interaction with HTFA, favoring its decoordination. ${ }^{36,37}$
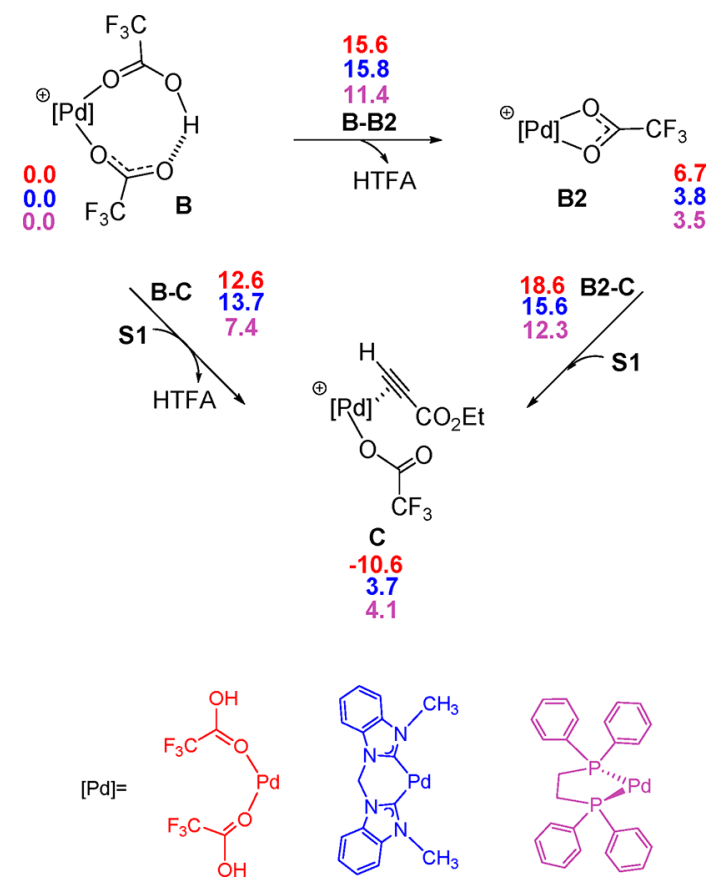

Figure 2. S1 coordination to Pd via one-step $(\mathbf{B} \rightarrow \mathbf{C})$ and two-step $(\mathbf{B} \rightarrow \mathbf{B} 2 \rightarrow \mathbf{C})$ pathways for the three investigated catalysts. Numbers are free energies in $\mathrm{CH}_{2} \mathrm{Cl}_{2}$ in $\mathrm{kcal} / \mathrm{mol}$.

On the other side, the stepwise pathway involves the decoordination of HTFA and the formation of a temporary $\kappa^{2}$-carboxylate species (B2). Starting from B2, S1 coordinates to the metal by breaking this chelate interaction. For all the three systems, the one-step $\mathbf{B} \rightarrow \mathbf{C}$ pathway is favored over the two-step pathway. However, while, for $\mathbf{2 A}$ and $\mathbf{3 A}$, the $\mathbf{C}$ intermediate is slightly higher in energy relative to $\mathbf{B}+\mathbf{S} \mathbf{1}(\Delta G$ $=3.7$ and $4.1 \mathrm{kcal} / \mathrm{mol}$ for $\mathbf{2 A}$ and $3 \mathbf{A}$, respectively), for $\mathbf{1 A}$, it is favored by $10.6 \mathrm{kcal} / \mathrm{mol}$. This difference is ascribed to the electronic effects of the ancillary ligand lying in a position trans to the coordinated alkyne. In details, the di-NHC and the DPPE ligands have a stronger trans effect and therefore they weaken the $\mathrm{Pd}-\mathrm{S} 1$ bond to a greater extent $\left(\mathrm{Pd}-\mathrm{C}_{\mathrm{S} 1}\right.$ distances are 2.14/2.15, 2.25/2.31, and 2.26/2.35 $\AA$ for 1A, 2A, and 3A, respectively).

Formation of the Z-Arylalkene (P1) Catalyzed by $1 \mathrm{~A}$. In this section, we discuss the complete catalytic cycle starting from intermediate $\mathbf{C}$ in the case of precatalyst $\mathbf{1 A}$; see Figure 3.

The nucleophilic addition of pentamethylbenzene (S2) to $\mathbf{S 1}$ to form the vinyl-Pd complex E proceeds in two steps. At first, a syn/anti nucleophilic attack of S2 to the C-C triple bond involving a low energy barrier leads to a very stable $\sigma$ arylalkenyl-Pd complex $\mathbf{D}$ (at least $25 \mathrm{kcal} / \mathrm{mol}$ more stable than $\mathrm{C}$ ), namely, the Wheland intermediate, as reported by Tunge et al. ${ }^{27}$

As in Figure 3, although the D-anti product is $3.6 \mathrm{kcal} / \mathrm{mol}$ less stable than the D-syn product, the energy barrier for its formation is favored by almost $6 \mathrm{kcal} / \mathrm{mol}$. From $\mathrm{D}$, a proton transfer from the $\mathrm{C}_{\mathrm{ipso}}$ atom of the arenium to the oxygen of the TFA ligand leads to the formation of $\mathbf{E}$ with a barrier of 19.7 and $26.8 \mathrm{kcal} / \mathrm{mol}$ from the D-anti and D-syn, respectively.

Both results are in agreement with the experimentally favored formation of $\mathbf{P} \mathbf{1}$ rather than the corresponding isomer $E$-arylalkenyl, as reported by Fujiwara et al. ${ }^{26,27,38}$ 

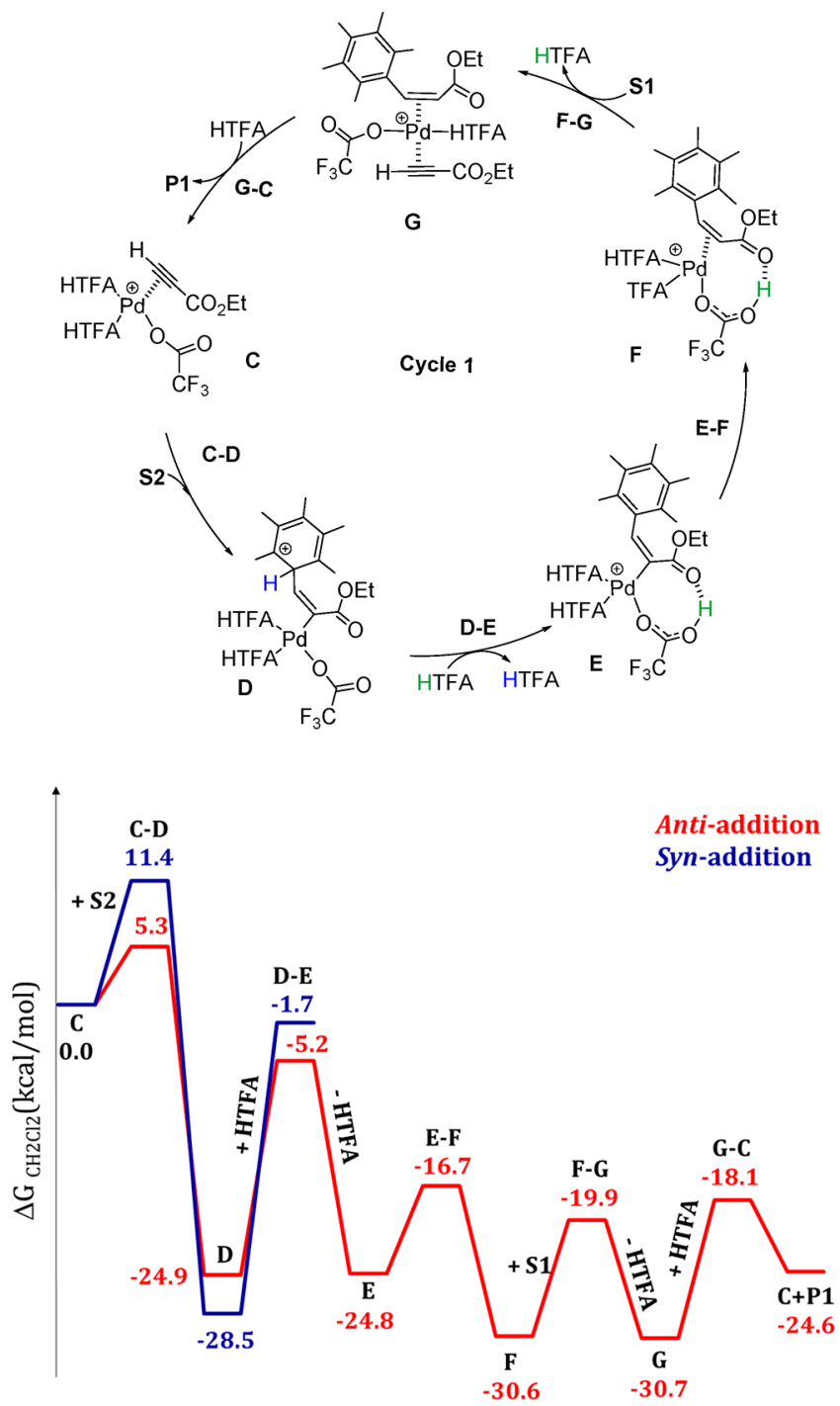

Figure 3. Catalytic cycle, at the top, and energy profiles (free energies in $\mathrm{kcal} / \mathrm{mol}$ ), at the bottom, for the hydroarylation of S1 (anti and syn S2 addition pathway in red and blue in the energy profile, respectively) in the presence of $\mathbf{1 A}$. All the species in the catalytic cycle are cationic.

Even though the barriers involved in the first step are at least $15 \mathrm{kcal} / \mathrm{mol}$ lower than those calculated for the latter, the selectivity between the two isomers occurs mainly in the C-D transition state: the much lower energy barrier for C-D-anti is ascribed to the approach of $\mathbf{S} 2$ occurring trans to Pd, which reduces the steric stress between the aromatic ring and the alkenyl-Pd (see Figure 4). Conversely, in C-D-syn, short distances (2.90 and $2.80 \AA$ ) between the $\mathbf{S 1}$ and $\mathbf{S 2}$ carbon atoms are found.

On the basis of the computed energy barriers, we excluded the formation of E-syn and, thus, we investigated the following steps of the catalytic cycle only for the formation of P1. It is worth to note that the formation of the neutral intermediate proposed by Tunge et al. ${ }^{27}$ (see $\mathbf{E}^{\prime}$ in Scheme 2) is calculated to be unfavored by $30 \mathrm{kcal} / \mathrm{mol}$ over intermediate $\mathbf{E}$.

From E, at $-24.8 \mathrm{kcal} / \mathrm{mol}$ from the starting species $\mathbf{C}+\mathbf{S 2}$ considered at infinite distance, the system evolves to the next intermediate $\mathbf{F}$ containing the coordinated olefin product through the protonolysis step E-F.
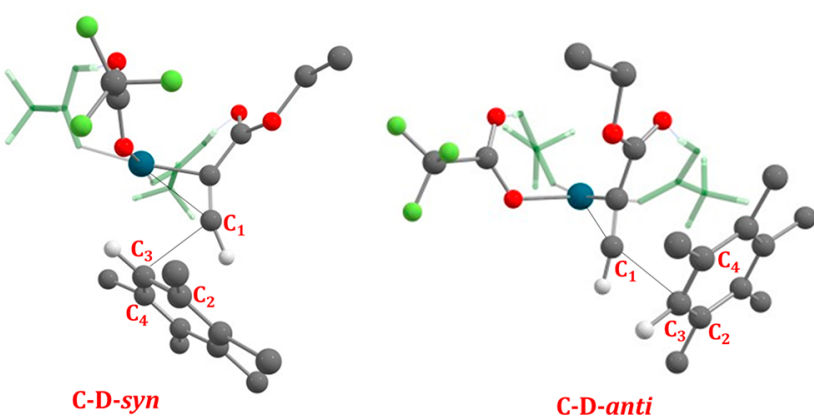

C-D-anti

Figure 4. Optimized geometry of transition states C-D-syn and C-Danti (C-D-syn, $\mathrm{C}_{1}-\mathrm{C}_{2} 2.90 \AA \mathrm{C}_{1}-\mathrm{C}_{4} 2.80 \AA \mathrm{C}_{1}-\mathrm{C}_{3} 2.56 \AA$; C-Danti: $\left.\mathrm{C}_{1}-\mathrm{C}_{2} 2.93 \AA, \mathrm{C}_{1}-\mathrm{C}_{4} 3.26 \AA \mathrm{C}_{1}-\mathrm{C}_{3} 2.72 \AA\right)$. The two molecules of HTFA are portrayed as green tubes. ${ }^{39}$

Different pathways have been investigated for this proton transfer reaction. A one-step and a stepwise reaction, via a sixmembered transition state (see Figure S1a) or two consecutive $[1,2]-\mathrm{H}$ shift steps as proposed by Marco-Contelles et al. ${ }^{28}$ (see Figure S1b), respectively, have been studied as intramolecular pathways. An intermolecular protonolysis reaction involving an external solvent molecule has also been considered, taking into account a one-step proton migration from the arenium to the $\mathrm{C}$ of the vinyl-Pd mediated by the external acid molecule (see Figure S1c) or a stepwise mechanism as proposed by Tunge et al. ${ }^{27}$ (Figure S1d). The one-step intramolecular protonolysis, with an energy barrier of $7.9 \mathrm{kcal} / \mathrm{mol}$, is favored by $20.0 \mathrm{kcal} / \mathrm{mol}$ over the double $[1,2]-\mathrm{H}$ shift intramolecular reaction and by 4.0 and $7.0 \mathrm{kcal} /$ mol over the one-step and the stepwise intermolecular reactions, respectively.

The following P1 dissociation proceeds in two steps; see Figure 3. At first, HTFA is displaced by the coordination of a new $\mathbf{S} 1$ molecule through a square pyramid transition state (FG) with the leaving acid occupying the apical position at almost 2.55 A from the metal and a free energy barrier of 10.7 $\mathrm{kcal} / \mathrm{mol}$. After formation of $\mathbf{G}$, in equilibrium with $\mathbf{F}$, the starting species $\mathbf{C}$ is regenerated by displacement of $\mathbf{P 1}$ and concomitant recoordination of a HTFA molecule (for G-C, $\left.\Delta G^{\ddagger}=12.6 \mathrm{kcal} / \mathrm{mol}\right)$.

Overall, the rate-determining step is the formation of the vinyl-Pd intermediate $\mathbf{E}$ that is obtained selectively from an anti-addition of S2. Even though this result is in contrast with the conclusions reported by Tunge and Foresee ${ }^{27}$ and by Soriano and Marco-Contelles, ${ }^{28}$ they both investigated intramolecular hydroarylations that can contemplate a more energy demanding protonolysis step becoming, as consequence, ratedetermining.

Formation of the Z-Arylalkene (P1) Catalyzed by $2 \mathrm{~A}$. In this section, we focus on the reaction mechanism/energies when system $\mathbf{2 A}$ is used as precatalyst; see Figure 5.

Starting from C, differently from catalyst $\mathbf{1 A}$, for $\mathbf{2 A}$, the formation of intermediate $\mathbf{E}$ occurs by the syn/anti-addition of S2 to the $\mathrm{C}-\mathrm{C}$ triple bond, followed by a spontaneous breaking of the aryl $\mathrm{C}-\mathrm{H}$ bond with the $\mathrm{H}$ transferring, at first, on the carboxylate group, and then on the TFA group (see Figure S2 in the Supporting Information). Transition state C-E requires a free energy barrier of 13.2 and $22.7 \mathrm{kcal} / \mathrm{mol}$ for the anti and syn-addition, respectively. The almost $10 \mathrm{kcal} / \mathrm{mol}$ in favor of the anti-addition, ascribed to the most favorable trans orientation between the arene and the alkenyl-Pd, makes this step selective, in agreement with the experimentally preferred 

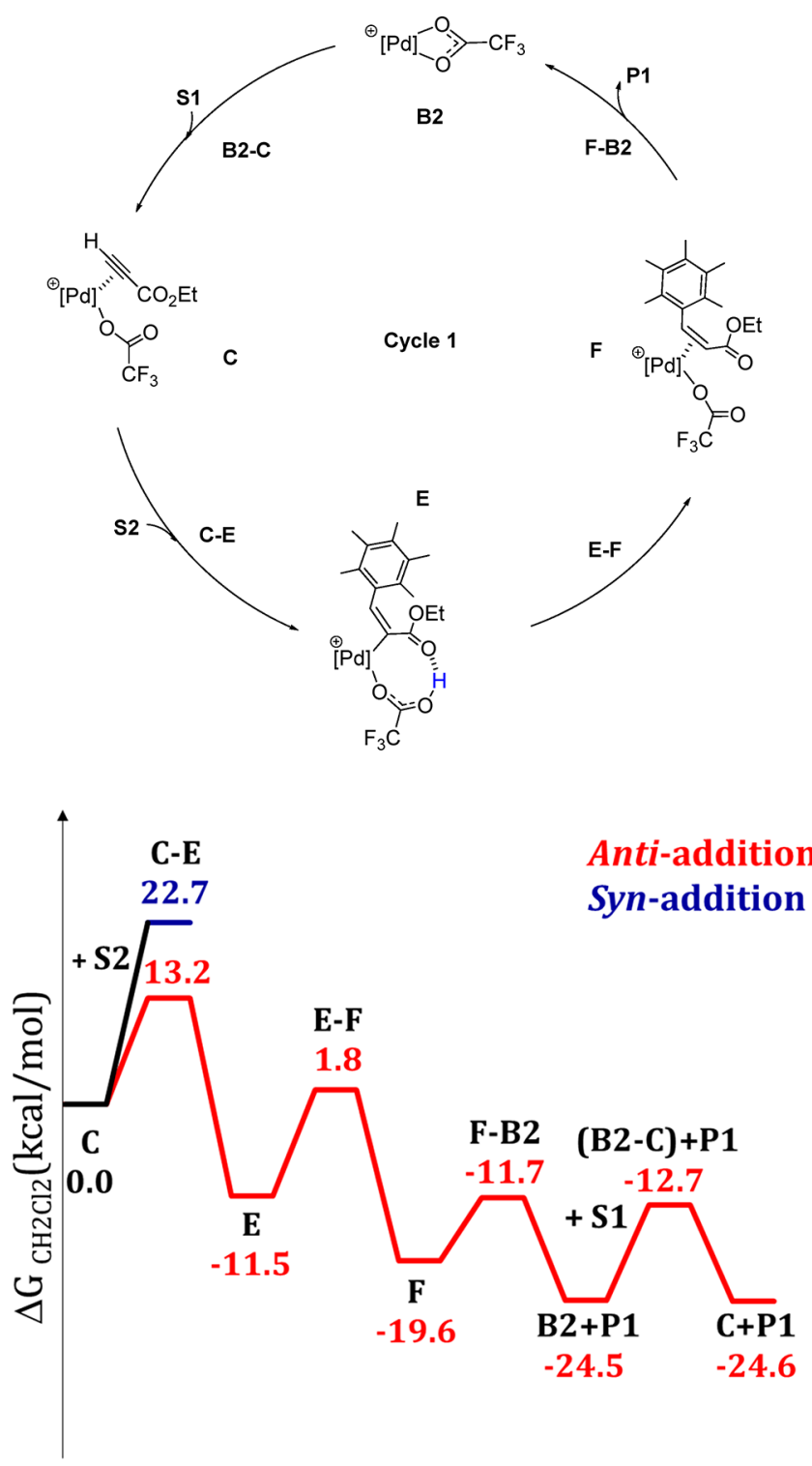

Figure 5. Catalytic cycle, at the top, and energy profiles (free energies in $\mathrm{kcal} / \mathrm{mol}$ ), at the bottom, for the hydroarylation of S1 (anti S2 addition pathway in red and syn-addition pathway in blue in the energy profile, respectively) in the presence of $\mathbf{2 A}$. $[\mathrm{Pd}]=$ diNHC-Pd.

formation of P1, as observed for system 1A. It is worth noting that, for $\mathbf{2 A}$, the formation of the Wheland intermediate $\mathbf{D}$ was ruled out since transition state $\mathbf{C}-\mathbf{D}$ is calculated to be kinetically unfavored by $4 \mathrm{kcal} / \mathrm{mol}$ over the direct formation of the vinyl intermediate $\mathbf{E}$. This decisive difference between 1A and $\mathbf{2 A}$ is ascribable to the presence of a HTFA ligand in the coordination sphere of the metal for 1A. As can be noted in Figure 4, a hydrogen bond interaction between one HTFA and the ethyl propiolate substituent stabilizes the negative charge delocalized on the ester group after arene addition in the case of $\mathbf{1 A}$. The absence of this interaction for $2 \mathrm{~A}$ brings the ester group to interact with the arenic hydrogen during the nucleophilic attack of S2 to S1, leading to the weakening of the $\mathrm{C}_{\mathrm{ipso}}-\mathrm{H}$ bond and promoting the spontaneous proton transfer in intermediate E. It is worth to note that, since the mentioned $\mathrm{H}$ transfer in the $\mathbf{E}$ product involves the anion on $\mathrm{Pd}$, the strength of the acid/base pair is expected to affect this step and the overall reaction rate, as discussed below. As for
1A, the strong kinetic preference for the anti-pathway allowed us to exclude the formation of E-syn and to investigate the following steps only for the anti-pathway.

From E, favored by more than $10 \mathrm{kcal} / \mathrm{mol}$ with respect to the starting species $\mathbf{C}+\mathbf{S} \mathbf{2}$ considered at infinite distance, the system undergoes to the protonolysis step E-F through the one-step intramolecular pathway with an energy barrier of 13.3 $\mathrm{kcal} / \mathrm{mol}$.

From F, differently from $\mathbf{1 A}, \mathbf{P} \mathbf{1}$ is displaced by an $\eta^{2}$ coordination of TFA, leading to the formation of the $\kappa^{2}$ carboxylate species B2. In transition state F-B2, the complex assumes a distorted square pyramid geometry with the leaving $Z$-arylalkene occupying the apical position at almost $2.8 \AA$ far from the metal and a free energy barrier of $7.9 \mathrm{kcal} / \mathrm{mol}$. After displacement of P1 (i.e., formation of B2), the starting species $\mathbf{C}$ is regenerated via breaking of the chelate interaction in $\mathbf{B 2}$ by coordination of a new molecule of $\mathbf{S 1}$ (for B2-C, $\Delta G^{\ddagger}=$ $11.8 \mathrm{kcal} / \mathrm{mol})$.

Overall, C-E, which is the determining step for product selectivity and for the reaction rate, is almost $6 \mathrm{kcal} / \mathrm{mol}$ lower with respect to the determining step in the presence of $\mathbf{1 A}$, in agreement with the higher activity found for $2 \mathrm{~A}$ with respect to $1 \mathrm{~A}$ under the same experimental conditions. ${ }^{34}$ It is worth to highlight that, differently from $\mathbf{2 A}$, for $\mathbf{1 A}$, the acid is involved in all the steps of the cycle since it acts also as an ancillary ligand on Pd.

Formation of the Z-Arylalkene (P1) Catalyzed by $3 A$. For system $3 \mathrm{~A}$, only the determining steps in the catalytic cycle have been calculated. Similarly to system 2A, starting from C, the nucleophilic addition of $\mathbf{S} 2$ to the $\mathrm{C}-\mathrm{C}$ triple bond occurs concomitant with the breaking of the $\mathrm{C}-\mathrm{H}$ bond and the proton migration from the arene to the TFA, and the antiproduct is formed selectively. The key energy barrier for the two catalysts differs only by $1-2 \mathrm{kcal} / \mathrm{mol}$, in agreement with their comparable experimental activity.,

Formation of the (1E,3Z)-Butadiene (P2) Catalyzed by 2A. In this section, the competitive catalytic cycle (Cycle 2) leading to the formation of $\mathbf{P 2}$ has been investigated for catalyst 2A. Both Cycles 1 and 2 with the corresponding energy profiles are reported in Figure 6 to facilitate the comparison between the two pathways.

Cycle 2 starts from the vinyl-Pd intermediate E. Since we have already observed that the formation of $\mathrm{E}$ occurs selectively by anti-addition of $\mathbf{S} 2$ in the step C-E, here we only discuss the anti-pathway of Cycle 2 .

From E, the coordination of the second molecule of $\mathbf{S 1}$ leads to the simultaneous decoordination of HTFA through transition state E-H. The energy barrier for this step is 13.6 $\mathrm{kcal} / \mathrm{mol}$, almost isoenergetic with the competitive protonolysis step in Cycle 1 (E-F). Formation of intermediate $\mathbf{H}$ is thermodynamically unfavored by $8.0 \mathrm{kcal} / \mathrm{mol}$ with respect to $\mathbf{E}$ and by $16.1 \mathrm{kcal} / \mathrm{mol}$ with respect to $\mathbf{F}$. The following $\mathbf{S 1}$ insertion into the $\mathrm{Pd}-\mathrm{C}$ bond leads to the formation of the vinyl-Pd intermediate I with a free energy barrier of $2.0 \mathrm{kcal} /$ mol. From I, the system evolves toward the release of P2 through low energy barriers and thermodynamically stable intermediates: one external HTFA molecule coordinates to the metal (I-L) and transfers the proton during the following protonolysis step with a barrier of only $10.7 \mathrm{kcal} / \mathrm{mol}$ (L-M). The last two steps of the cycle take place similarly to what is described for Cycle 1, i.e., decoordination of the product with formation of the $\kappa^{2}$-carboxylate species $\mathbf{B 2}$ and coordination of a new molecule of $\mathbf{S} 1$. 

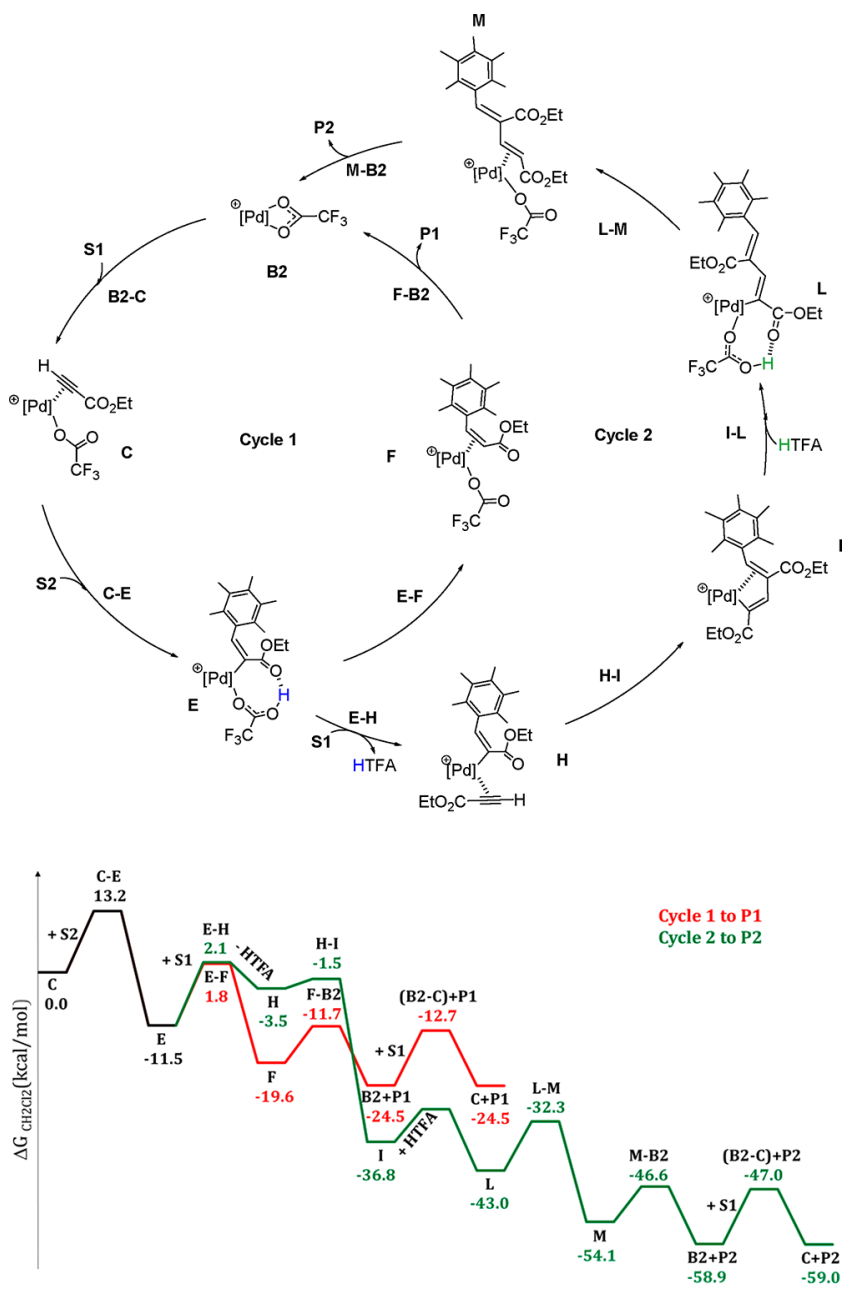

Figure 6. Catalytic cycle, at the top, and energy profiles (free energies in $\mathrm{kcal} / \mathrm{mol}$ ), at the bottom, for the hydroarylation of S1 to P1 (in red) and to $\mathbf{P 2}$ (in green) in the presence of $\mathbf{2 A}$. [Pd] = diNHC-Pd.

The comparison of the two catalytic cycles suggests that the system prefers to evolve toward the protonolysis E-F rather than toward the coordination of a second molecule of S1. In fact, from $\mathbf{E}$, the common intermediate for the two pathways, the thermodynamic favors Cycle 1 by almost $10 \mathrm{kcal} / \mathrm{mol}$, in agreement with the experimentally favored formation of P1 with respect to $\mathbf{P 2}$ in the presence of $\mathbf{2 A}(\mathbf{P 1} / \mathbf{P 2}$ ratio of $75 /$ 2).

Formation of the (1E,3Z)-Butadiene (P2) Catalyzed by 3A. Since the experimental results showed that $3 \mathbf{A}$ mainly produces P2 (P1/P2 ratio of 9/82), based on the considerations reported in the previous section, we only discuss the two competitive E-F (Cycle 1) and E-H (Cycle 2) steps.

As for $2 \mathrm{~A}, \mathrm{~F}$ is strongly thermodynamically favored with respect to $\mathbf{H}$ by almost $10 \mathrm{kcal} / \mathrm{mol}$. However, differently from 2A, starting from $\mathbf{E}$ (formed selectively as E-anti product), E$\mathbf{H}$ is almost $9 \mathrm{kcal} / \mathrm{mol}$ lower than E-F. This kinetic preference for Cycle 2 pushes the system toward the coordination of a further molecule of $\mathbf{S 1}$ rather than to the protonolysis, in agreement with the experiments.

Comparison between $2 \mathrm{~A}$ and $3 \mathrm{~A}$. To rationalize the substantial difference between $\mathbf{2 A}$ and $\mathbf{3 A}$ toward the competition between the two catalytic cycles, we have performed both a steric and an electronic analysis.
From a steric point of view, even though overall the di-NHC ligand is less sterically hindered than the DPPE, the greater tightness of the di-NHC determines a higher steric pressure in the close proximity of the Pd center with the carbenic carbons found at short distances from the aryl-alkenyl bound to the metal. This effect is particularly relevant in the crowded transition state E-H that, as consequence, is unfavored to a larger extent with respect to E-F for $\mathbf{2 A}$ than for $\mathbf{3 A}$ (see short distances in Figure 7).

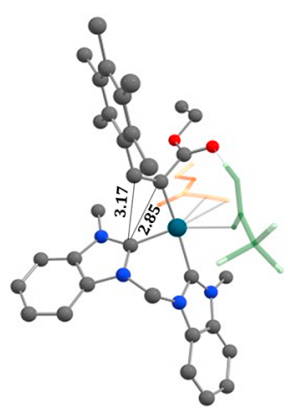

E-H for $2 \mathrm{~A}$

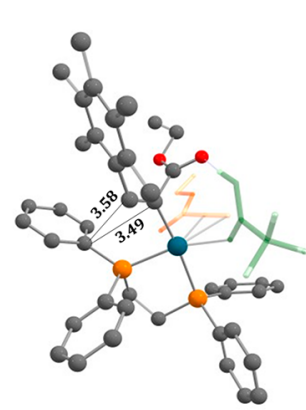

E-H for $3 A$
Figure 7. Optimized geometries of transition state $\mathbf{E}-\mathbf{H}$ for $\mathbf{2 A}$ (on the left) and $3 \mathrm{~A}$ (on the right) and key distances (in $\AA$ ). In green and orange tubes are reported the HTFA and the alkyne molecule, respectively. ${ }^{40}$

From an electronic point of view, all the species along the catalytic cycle show a lower positive charge on $\mathrm{Pd}$ for $\mathbf{3 A}$ with respect to 2A; see Table $\mathrm{S} 1$. As consequence, the $\mathrm{Pd}-\mathrm{O}$ bond trans to the ligand is weaker for $\mathbf{3 A}$ than $\mathbf{2 A}$, favoring the release of the acid moiety and decreasing the energy of the E-H transition state. This effect is confirmed also by the decrease of the $\Delta G$ between $\mathbf{F}$ and $\mathbf{H}$ from $-16 \mathrm{kcal} / \mathrm{mol}$ for $\mathbf{2 A}$ to -10 $\mathrm{kcal} / \mathrm{mol}$ for $3 \mathrm{~A}$ due to the higher destabilization of the $\mathrm{Pd}-\mathrm{O}$ bond in 3A.

Formation of the (1E,3Z)-Butadiene (P2) Catalyzed by $2 \mathrm{~A}$ in the Presence of $\mathrm{HBF}_{4}$. In order to explain how the acid affects the product selectivity, we performed calculations on the hydroarylation of S1 with $\mathbf{S} 2$ for catalyst $\mathbf{2 A}$ in the presence of $\mathrm{HBF}_{4}$ (Figure 8). Indeed, it has been experimentally demonstrated that, under these conditions, the reaction selectivity of $\mathbf{2 A}$ switches toward formation of P2. ${ }^{41}$

Starting from the formation of the active species, as previously reported, the reaction occurs by coordination of S1 with the concomitant release of one molecule of acid of the precatalyst and formation of intermediate C. Although this reaction turned out to be thermodynamically unfavored in the presence of HTFA, with $\mathrm{HBF}_{4}$, the formation of intermediate C is favored by almost $6 \mathrm{kcal} / \mathrm{mol}$, suggesting an easier initiation process in agreement with the higher experimental activity in the presence of $\mathrm{HBF}_{4}$. This difference is ascribed to the greater steric hindrance and lower Lewis basicity of $\mathrm{HBF}_{4}$ with respect to HTFA that favors the decoordination of the acid and the coordination of $\mathbf{S} 1$.

From $\mathbf{C}$, the favored pathway consists in the formation of intermediate $\mathbf{E}$ by syn/anti-addition of the aryl-hydrogen bond of $\mathbf{S} \mathbf{2}$ to the $\mathrm{C}-\mathrm{C}$ triple bond with concomitant breaking of the $\mathrm{C}-\mathrm{H}$ bond and $\mathrm{H}$ migration from the arene to the ethyl propiolate. The free energy barriers of 19.4 and $27.6 \mathrm{kcal} / \mathrm{mol}$ for the anti- and syn-addition, respectively, make this step 

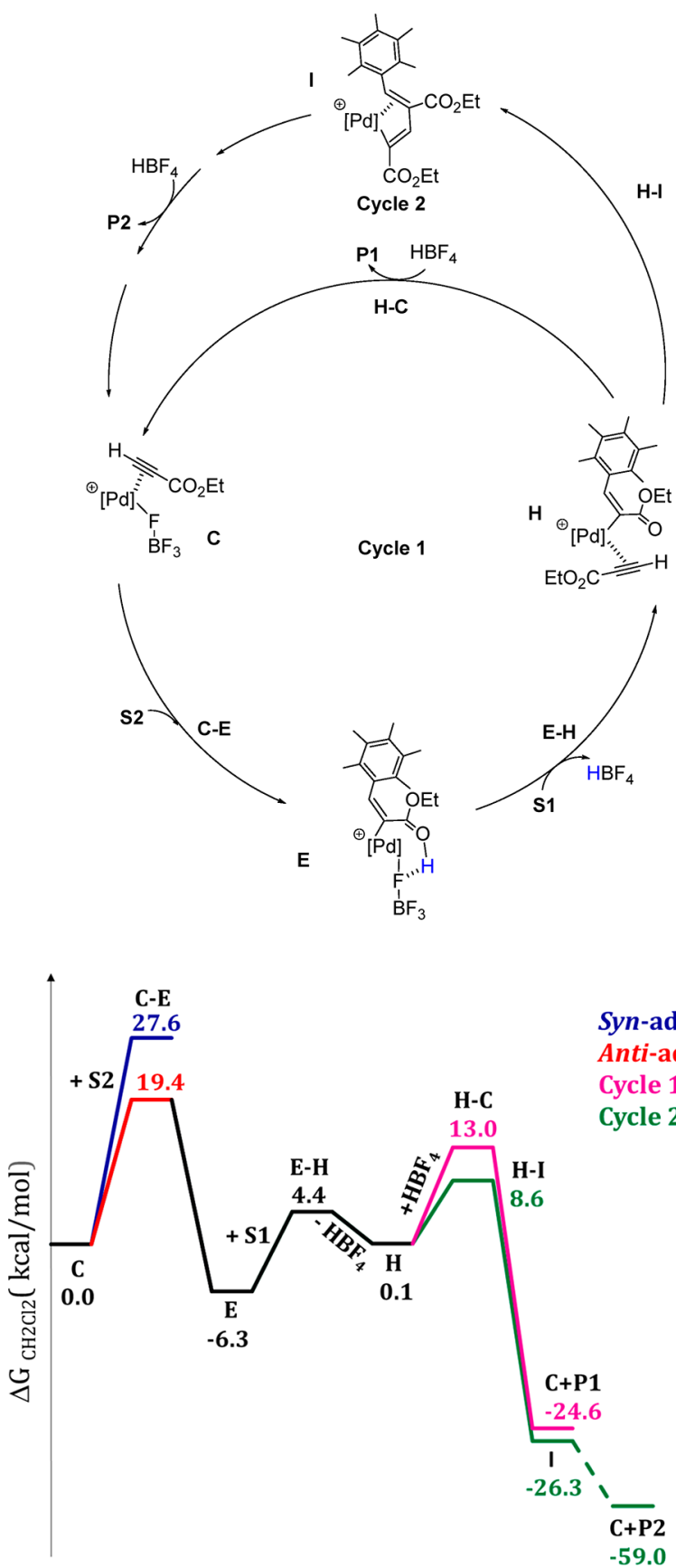

Figure 8. Catalytic cycle, at the top, and energy profiles (free energies in $\mathrm{kcal} / \mathrm{mol}$ ), at the bottom, for the hydroarylation of S1 (anti and syn S2 addition pathway in red and blue in the energy profile, respectively; $\mathbf{S 1}$ second addition pathway in green, protonolysis in purple) in the presence of $2 \mathrm{~A}$ and $\mathrm{HBF}_{4}$. [Pd] = diNHC-Pd.

selective, in agreement with the experimentally preferred formation of the product with $Z$ stereochemistry (as already observed in the presence of HTFA).

From E, the coordination of the second molecule of $\mathbf{S} \mathbf{1}$ with simultaneous decoordination of $\mathrm{HBF}_{4}$ through transition state E-H requires a barrier of only $10 \mathrm{kcal} / \mathrm{mol}$ and, contrary to what was observed in the presence of HTFA, is kinetically favored with respect to the protonolysis reaction. This different behavior is the result of the weaker coordination of $\mathrm{HBF}_{4}$ to $\mathrm{Pd}$ with respect to HTFA. Nevertheless the formation of $\mathbf{H}$ is unfavored by almost $6 \mathrm{kcal} / \mathrm{mol}$ with respect to $\mathrm{E}$, the following $\mathbf{S} \mathbf{1}$ insertion into the $\mathrm{Pd}-\mathrm{C}$ bond with a free energy barrier of only $8.5 \mathrm{kcal} / \mathrm{mol}$ leads to the formation of the very stable vinyl-Pd intermediate I (at $-26.3 \mathrm{kcal} / \mathrm{mol}$ with respect to $\mathbf{C}$ ) driving the reaction toward the release of $\mathbf{P 2}$.

Interestingly, starting from $\mathbf{H}$, we located an alternative pathway leading to the release of P1 (forming a new Cycle 1). This pathway consists in an intermolecular proton transfer that takes place through a one-step mechanism ( $\mathbf{H}-\mathbf{C})$ involving an external $\mathrm{HBF}_{4}$ molecule. The acid molecule adds to the $\mathrm{Pd}-\mathrm{C}$ bond, releasing the proton to the carbon and coordinating the anion to the metal center with a barrier of $13 \mathrm{kcal} / \mathrm{mol}$ with respect to $\mathbf{H}$. This pathway was ruled out for system $\mathbf{2 A}$ in the presence of HTFA for the high energy barrier calculated, i.e., almost $30 \mathrm{kcal} / \mathrm{mol}$ with respect to $\mathbf{H}$.

The comparison of the energies of the two catalytic cycles suggests that system $2 \mathrm{~A}$ in the presence of $\mathrm{HBF}_{4}$ prefers to evolve toward the coordination/insertion of a second molecule of $\mathbf{S 1}$ rather than the formation of $\mathbf{P 1}$, in agreement with the experimentally favored formation of $\mathbf{P 2}$ (P1/P2 ratio equal to 7/43). ${ }^{3}$

The meaningful difference of energy between the two competitive transition states $\mathbf{H}-\mathbf{C}$ and $\mathbf{H}-\mathbf{I}$ (almost $5 \mathrm{kcal} / \mathrm{mol}$ ) is ascribed to the inefficient coordination of $\mathrm{HBF}_{4}$ to the metal that increases the energy of $\mathbf{H}-\mathbf{C}$ and favors instead the insertion of S1 (H-I).

In conclusion, the different selectivity toward $\mathbf{P 2}$ and $\mathbf{P 1}$ in the presence of $\mathrm{HTFA} / \mathrm{TFA}$ and $\mathrm{HBF}_{4} / \mathrm{BF}_{4}$ for $\mathbf{2 A}$ is explained upon considering the different coordination ability of the acid/ base pairs, rather than the strength of the acid, in agreement with the experimental results obtained for the system $2 \mathrm{~A}$ in the presence of various acids with different strength and coordination ability. ${ }^{7}$ However, such a selectivity switch is also critically dependent on the steric hindrance provided by the di-NHC ligand in $\mathbf{2 A}$; this is apparent when one considers that use of the catalytic system $\mathbf{1 A}$ with $\mathrm{HBF}_{4}$ results in a less active catalytic system compared to $\mathbf{2 A}$, and most notably in a reaction selectivity that provides almost exclusively the product of single alkyne insertion.

It is worth to highlight that the rate-determining step in the presence of $\mathrm{HBF}_{4}$ is almost $6 \mathrm{kcal} / \mathrm{mol}$ higher than in the presence of HTFA. This difference is directly related to the strength of the acid involved, as already anticipated above. Since the mentioned determining step implies the transfer of a proton from the arene to the ethyl propiolate substituent assisted by the anion ligand (TFA or $\mathrm{BF}_{4}$ ), the higher basicity of TFA (given the lower acidity of HTFA) with respect to $\mathrm{BF}_{4}$ helps the transition from an alkyne coordinated species $(\mathrm{C})$ to a vinyl-Pd one $(\mathrm{E})$, decreasing the rate-determining barrier $\mathrm{C}$ E.

\section{CONCLUSIONS}

The detailed mechanism of the hydroarylation of ethyl propiolate via $\mathrm{C}-\mathrm{H}$ activation of pentamethylbenzene in the presence of three different palladium complexes and two different acids has been discussed here.

The calculations performed indicate a Friedel-Craft type mechanism as the most likely to occur: the alkyne is activated by coordination to the metal with the following addition of the aromatic ring promoting the proton transfer to the alkyne and the formation of a vinyl-palladium intermediate. The final onestep intramolecular protonolysis of the vinyl-palladium liberates the product and regenerates the catalyst. 
The arene addition step is found to be rate-determining, but its precise nature strongly depends on the ligands coordinated to the metal. For instance, for the $\mathrm{Pd}(\mathrm{OAc})_{2} / \mathrm{HTFA}$ system, a two-step mechanism involving the formation of a Whelandtype intermediate occurs. On the contrary, a one-step mechanism consisting in the arene addition concerted with the hydrogen transfer from the arene to the alkyne assisted by the anionic ligand coordinated to the metal is preferred in the case of (di-NHC) PdX $2 /$ HTFA and (dppe) Pd(OAc) $)_{2}$ systems. This difference is mainly ascribed to the hydrogen bond interactions establishing in the coordination sphere of the metal when the acid molecule acts also as ligand, as in the case of the former system. The one-step addition mechanism features a lower energy barrier and is consequently coherent with the higher catalytic activity exhibited by (di-NHC) $\mathrm{PdX}_{2} /$ HTFA and (dppe)Pd(OAc) 2 .

The syn/anti selectivity of the arene addition step strongly depends on the steric crash between the aromatic ring and the Pd-alkyne $\pi$ complex, with the trans-addition leading to the $Z$ arylalkene product being favored over the cis one for all the catalysts studied.

On the other hand, the selectivity toward the formation of single or double alkyne insertion products depends on a strict combination of both steric and electronic features of the ligands as well as of the employed acid cocatalyst. For instance, from an electronic point of view, strong $\sigma$ donor ligands, such as dppe, weaken the $\mathrm{Pd}$-acid bond to a greater extent, favoring the release of the acid moiety and the coordination of the second ethyl propiolate. In the case of the di-NHC ligand, the steric factors are predominant: a greater tightness in close proximity of the metal unfavors the space demanding transition state for the addition of another molecule of ethyl propiolate determining the selectivity toward the formation of arylalkenes.

The performed studies allowed also rationalizing the effect of the acid on the catalyst performances. In detail, the experimentally observed higher reaction rate in the presence of $\mathrm{HBF}_{4}$ is ascribed to the thermodynamically more favored formation of the alkyne coordinating species $\mathbf{C}$, thanks to the easier release of one molecule of $\mathrm{HBF}_{4}$ with respect to HTFA, which results in a higher concentration of catalytically competent species.

Instead, the actual activation barrier in the catalytic cycle increases by decreasing the acid strength, since the proton transfer from the arene to the ethyl propiolate in the ratedetermining step of the reaction is more efficient the more basic is the anionic ligand in the catalyst (i.e., the weaker is the corresponding acid). Finally, the selectivity toward the single and double alkyne insertion is mainly affected by the coordinating power of the acid/base pairs, with a low coordinating acid (as $\mathrm{HBF}_{4}$ ) that is more easily displaced by the second alkyne in the Pd coordination sphere, thus favoring the double insertion product.

\section{EXPERIMENTAL SECTION}

Computational Details. All the DFT static calculations were performed with the Gaussian 09 quantum chemistry package. ${ }^{42}$ The electronic configuration of the molecular system was described with the standard split-valence basis set with a polarization function of Ahlrichs and co-workers for H, C, N, F, P, and O (SVP keyword in Gaussian 09). ${ }^{43}$ For Pd, we used the small core, quasi relativistic Stuttgart/Dresden effective core potential, with an associated valence basis set contracted (standard SDD keywords in Gaussian 09). ${ }^{44}$ The geometry optimizations were carried out without symmetry constraints, and the characterization of the located stationary points was performed by analytical frequency calculations, by using the BP86 functional of Becke and Perdew. ${ }^{45,46}$ Gibbs energies reported in the reported figures, $\Delta G$, were built through single point energy

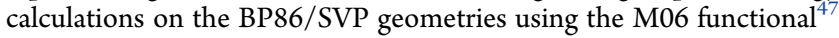
and the triple- $\zeta$ valence plus polarization on main group atoms (TZVP keyword in Gaussian), ${ }^{48}$ whereas, for Pd, the SDD basis set was employed. Solvent effects were included with the polarizable continuous solvation model PCM using $\mathrm{CH}_{2} \mathrm{Cl}_{2}$ as the solvent. ${ }^{49}$ To these M06/TZVP electronic energies in solvent $\left(\mathrm{CH}_{2} \mathrm{Cl}_{2}\right)$, zero point energy and thermal and entropic corrections, evaluated at $298.15 \mathrm{~K}$ and $1.0 \mathrm{~atm}$, were included from the gas phase frequency calculations at the BP86/SVP level of theory.

\section{ASSOCIATED CONTENT}

\section{S Supporting Information}

The Supporting Information is available free of charge on the ACS Publications website at DOI: 10.1021/acs.organomet.9b00473.

\section{Alternative pathways investigated and $\mathrm{NBO}$ analysis (PDF) \\ Cartesian coordinates (XYZ)}

\section{AUTHOR INFORMATION}

\section{Corresponding Authors}

*E-mail: laura.falivene@kaust.edu.sa (L.F.).

*E-mail: lcaporaso@unisa.it (L.C.).

*E-mail: andrea.biffis@unipd.it (A.B.).

\section{ORCID}

Laura Falivene: 0000-0003-1509-6191

Luigi Cavallo: 0000-0002-1398-338X

Cristina Tubaro: 0000-0001-7724-735X

Andrea Biffis: 0000-0002-7762-8280

Notes

The authors declare no competing financial interest.

\section{ACKNOWLEDGMENTS}

The authors thank ENEA (http://www.enea.it) and the HPC team for support as for using the ENEA-GRID and the HPC facilities CRESCO (http://www.cresco.enea.it) Portici (Naples, Italy).

\section{REFERENCES}

(1) Catalytic Hydroarylation of Carbon-Carbon Multiple Bonds; Ackermann, L., Gunnoe, T. B., GojHabgood, L., Eds.; Wiley-VCH: Weinheim, Germany, 2018.

(2) Boyarskiy, V. P.; Ryabukhin, D. S.; Bokach, N. A.; Vasilyev, A. V. Alkenylation of Arenes and Heteroarenes with Alkynes. Chem. Rev. 2016, 116, 5894-5986.

(3) Biffis, A.; Tubaro, C.; Baron, M. Advances in Transition-MetalCatalysed Alkyne Hydroarylations. Chem. Rec. 2016, 16, 1742-1760.

(4) Yamamoto, Y. Synthesis of heterocycles via transition-metalcatalyzedhydroarylation of alkynes. Chem. Soc. Rev. 2014, 43, 1575160.

(5) Perhaps the term "direct hydroarylation" would be more appropriate, as formal alkyne hydroarylation products can be obtained also from other routes starting from, e.g., aryl halides.

(6) The Mizoroki-Heck Reaction; Oestreich, M., Ed.; Wiley: Hoboken, NJ, 2009.

(7) Oyamada, J.; Kitamura, T. Drastic effect of bidentate phosphine ligands on Pd-catalyzedhydroarylation of ethyl propiolate: a simple route to arylbutadienes. Chem. Commun. 2008, 4992-4994.

(8) Biffis, A.; Gazzola, L.; Gobbo, P.; Buscemi, G.; Tubaro, C.; Basato, M. Alkyne Hydroarylations with Chelating Dicarbene Palladium(II) Complex Catalysts: Improved and Unexpected 
Reactivity Patterns Disclosed Upon Additive Screening. Eur. J. Org. Chem. 2009, 2009, 3189-3198.

(9) Kitamura, T. Transition-Metal-CatalyzedHydroarylationReactions of AlkynesThrough Direct Functionalization of C-H Bonds: A ConvenientTool for OrganicSynthesis. Eur. J. Org. Chem. 2009, 2009, $1111-1125$.

(10) Nevado, C.; Echavarren, A. M. Transition Metal-CatalyzedHydroarylation of Alkynes. Synthesis 2005, 2005, 167-182.

(11) Wang, X.; Zhou, L.; Lu, W. Hydroarylation of Alkynes via Aryl C-H Bond Cleavage. Curr. Org. Chem. 2010, 14, 289-307.

(12) Li, B.; Dixneuf, P. H. Ruthenium (II)-Catalysed $\mathrm{sp}^{2}$ C-H Bond Functionalization by C-C Bond Formation. Top. Organomet. Chem. 2014, 48, 119-193.

(13) Manikandan, R.; Jeganmohan, M. Recent advances in the ruthenium-catalyzedhydroarylation of alkynes with aromatics: synthesis of trisubstituted alkenes. Org. Biomol. Chem. 2015, 13, 1042010436.

(14) Santhoshkumar, R.; Cheng, C.-H. Hydroarylations by cobaltcatalyzed C-H activation. Beilstein J. Org. Chem. 2018, 14, 2266-2288.

(15) Chernyak, N.; Gevorgyan, V. Exclusive 5-exo-dig Hydroarylation of $o$-AlkynylBiaryls Proceeding via $\mathrm{C}-\mathrm{H}$ Activation Pathway. J. Am. Chem. Soc. 2008, 130, 5636-5637.

(16) Gao, K.; Yoshikai, N. Low-Valent Cobalt Catalysis: New Opportunities for C-H Functionalization. Acc. Chem. Res. 2014, 47, 1208-1219.

(17) Ryu, J.; Cho, S. H.; Chang, S. A Versatile Rhodium(I) Catalyst System for the Addition of Heteroarenes to both Alkenes and Alkynes by a C-H Bond Activation. Angew. Chem., Int. Ed. 2012, 51, 36773681.

(18) Schipper, D. J.; Hutchinson, M.; Fagnou, K. Rhodium(III)Catalyzed Intermolecular Hydroarylation of Alkynes. J. Am. Chem. Soc. 2010, 132, 6910-6911.

(19) Nakao, Y. Hydroarylation of alkynes catalyzed by nickel. Chem. Rec. 2011, 11, 242-251.

(20) Blons, C.; Mallet-Ladeira, S.; Amgoune, A.; Bourissou, D. $\pi$ Complexes of P-P and P-N chelated gold(I). Angew. Chem., Int. Ed. 2018, 57, 11732-11736.

(21) Nakhi, A.; Archana, S.; Seerapu, G. P. K.; Chennubhotla, K. S.; Kumar, K. L.; Kulkarni, P.; Haldar, D.; Pal, M. AlCl3-mediated hydroarylation-heteroarylation in a single pot: a direct access to denselyfunctionalizedolefins of pharmacologicalinterest. Chem. Commun. 2013, 49, 6268-6270.

(22) Choi, D. S.; Kim, J. H.; Shin, U. S.; Deshmukh, R. R.; Song, C. E. Thermodynamically- and kinetically-controlled Friedel-Crafts alkenylation of arenes with alkynes using an acidic fluoroantimonate(V) ionic liquid as catalyst. Chem. Commun. 2007, 3482-3484.

(23) Song, C. E.; Jung, D.-u.; Choung, S. Y.; Roh, E. J.; Lee, S.-g. Dramatic Enhancement of Catalytic Activity in an Ionic Liquid: Highly Practical Friedel-Crafts Alkenylation of Arenes with Alkynes Catalyzed by Metal Triflates. Angew. Chem., Int. Ed. 2004, 43, 61836185.

(24) Tsuchimoto, T.; Maeda, T.; Shirakawa, E.; Kawakami, Y. Friedel-Crafts alkenylation of arenes using alkynes catalysed by metal trifluoromethanesulfonates. Chem. Commun. 2000, 1573-1574.

(25) Jia, C.; Dongguo, D.; Oyamada, J.; Lu, W.; Kitamura, T.; Fujiwara, Y. Efficient Activation of Aromatic C-H Bonds for Addition to C-C Multiple Bonds. Science 2000, 287, 1992-1995.

(26) Jia, C.; Lu, W.; Oyamada, J.; Kitamura, T.; Matsuda, K.; Irie, M.; Fujiwara, Y. Novel Pd (II)- and Pt (II)-CatalyzedRegio- and Stereoselective trans-Hydroarylation of Alkynes by Simple Arenes. J. Am. Chem. Soc. 2000, 122, 7252-7263.

(27) Tunge, J. A.; Foresee, L. N. Mechanistic Studies of Fujiwara Hydroarylation. C-H Activation versus Electrophilic Aromatic Substitution. Organometallics 2005, 24, 6440-6444.

(28) Soriano, E.; Marco-Contelles, J. Mechanisms of the Transition Metal-Mediated Hydroarylation of Alkynes and Allenes. Organometallics 2006, 25, 4542-4553.

(29) Schroeter, F.; Císarová, I.; Soellner, J.; Herdtweck, E.; Strassner, T. Electron-poor hemilabiledicationic palladium NHC complexes - synthesis, structure and catalytic activity. Dalton Trans. 2018, 47, $16638-16650$.

(30) Godoi, M. N.; de Azambuja, F.; Martinez, P. D. G.; Morgon, N. H.; Santos, V. G.; Regiani, T.; Lesage, D.; Dossmann, H.; Cole, R. B.; Eberlin, M. N.; Correia, C. R. D. Revisiting the Intermolecular Fujiwara Hydroarylation of Alkynes. Eur. J. Org. Chem. 2017, 2017, 1794-1803

(31) Hota, P. K.; Jose, A.; Mandal, S. K. Stereo- and Regioselective Addition of Arene to Alkyne Using Abnormal NHC Based Palladium Catalysts: Elucidating the Role of Trifluoroacetic Acid in Fujiwara Process. Organometallics 2017, 36 (22), 4422-4431.

(32) The acetate ligands substitution occurring in solution was calculated for 1A following the reaction: $\mathrm{Pd}(\mathrm{OAc})_{2}+4 \mathrm{HTFA}=$ $\mathrm{Pd}(\mathrm{HTFA})_{2}(\mathrm{TFA})_{2}+2 \mathrm{HOAc}$. The process is exoergonic by 16.0 $\mathrm{kcal} / \mathrm{mol}$.

(33) Muehlhofer, M.; Strassner, T.; Herrmann, W. A. New Catalyst Systems for the Catalytic Conversion of Methane into Methanol. Angew. Chem., Int. Ed. 2002, 41, 1745-1747.

(34) Biffis, A.; Tubaro, C.; Buscemi, G.; Basato, M. Highly Efficient Alkyne Hydroarylation with Chelating Dicarbene Palladium (II) and Platinum (II) Complexes. Adv. Synth. Catal. 2008, 350, 189-196.

(35) All the attempts to optimize the geometry with the S1 coordinated trans to TFA failed as proton transfer between TFA and HTFA occurs, leading to a cis coordinated geometry.

(36) Antonova, N. S.; Carbó, J. J.; Poblet, J. M. Quantifying the Donor-Acceptor Properties of Phosphine and N-Heterocyclic Carbene Ligands in Grubbs' Catalysts Using a Modified EDA Procedure Based on Orbital Deletion. Organometallics 2009, 28, 4283-4287.

(37) Getty, K.; Delgado-Jaime, M. U.; Kennepohl, P. An Electronic Rationale for Observed Initiation Rates in Ruthenium-Mediated Olefin Metathesis: Charge Donation in Phosphine and N-Heterocyclic Carbene Ligands. J. Am. Chem. Soc. 2007, 129 (51), 1577415776

(38) Jia, C.; Kitamura, T.; Fujiwara, Y. Catalytic Functionalization of Arenes and Alkanes via C-H Bond Activation. Acc. Chem. Res. 2001, 34, 633-639.

(39) The alternative conformers for transition states C-D-syn and CD-anti generated through rotation around the $\mathrm{C}_{1}=\mathrm{C}-\mathrm{CO}_{2} \mathrm{Et}$ single bond are $6.5 \mathrm{kcal} / \mathrm{mol}$ higher in energy with respect to transition state C-D reported in the paper; see Figure 4. The formation of an $\mathrm{H}$ bonding between the carbonyl oxygen of $\mathbf{S} \mathbf{1}$ and the acidic hydrogen HTFA is crucial in stabilizing the system.

(40) The alternative conformer for the E-H transition state in which the alkyne substrate is rotated $180{ }^{\circ} \mathrm{C}$ and the $\mathrm{EtO}_{2} \mathrm{C}$ group points towards the alkenyl group is unfavored for steric reasons, and the corresponding following intermediate $\mathbf{H}$ is $4.0 \mathrm{kcal} / \mathrm{mol}$ higher in energy than the one reported in the paper.

(41) We used the simple " $\mathrm{HBF}_{4}$ " model for this acid in order to simplify the calculations. However, we are aware that a more appropriate representation of such acid in solution would be $\mathrm{H}_{3} \mathrm{O}^{+} \mathrm{BF}_{4}^{-}$. To this extent, we have performed a series of benchmark calculations on key intermediates and transition states using for catalyst $2 \mathrm{~A}$ in the presence of $\mathrm{H}_{3} \mathrm{O}^{+} \mathrm{BF}_{4}{ }^{-}$. On the basis of the considerations reported in the paper, we calculated, starting from intermediate $\mathbf{H}$, the competitive $\mathbf{H}-\mathbf{C}$ (Cycle 1) and $\mathbf{H}-\mathbf{I}$ (Cycle 2) transition states. $\mathbf{H}-\mathbf{I}$ is calculated clearly lower in energy than $\mathbf{H}-\mathrm{C}$ as in the presence of the $\mathrm{HBF}_{4}$, indicating that the system prefers to evolve towards coordination/insertion of a second molecule of S1, leading to the preferential formation of P2, instead of undergoing protonolysis of the vinyl-pallladium. This is in agreement with the experiments. Therefore, these tests resulted only in minor numerical differences relative to calculations using $\mathrm{HBF}_{4}$, and no chemical conclusion is modified.

(42) Frisch, M. J.; Trucks, G. W.; Schlegel, H. B.; Scuseria, G. E.; Robb, M. A.; Cheeseman, J. R.; Scalmani, G.; Barone, V.; Mennucci, B.; Petersson, G. A.; et al. Gaussian 09, Revision D.01; Gaussian, Inc.: Wallingford, CT, 2009. 
(43) Schaefer, A.; Horn, H.; Ahlrichs, R. Fully optimized contracted Gaussian basis sets for atoms Li to Kr. J. Chem. Phys. 1992, 97, 25712577.

(44) Haussermann, U.; Dolg, M.; Stoll, H.; Preuss, H.; Schwerdtfeger, P.; Pitzer, R. M. Accuracy of energy-adjusted quasirelativistic ab initio pseudopotentials. Mol. Phys. 1993, 78, 1211-1224.

(45) Becke, A. Density-functional exchange-energy approximation with correct asymptotic behaviour. Phys. Rev. A: At., Mol., Opt. Phys. 1988, 38, 3098-3100.

(46) Perdew, J. P. Density-functional approximation for the correlation energy of the in homogeneous electron gas. Phys. Rev. B: Condens. Matter Mater. Phys. 1986, 33, 8822-8824.

(47) Zhao, Y.; Truhlar, D. G. The M06 suite of density functionals for main group thermochemistry, thermochemical kinetics, noncovalent interactions, excited states, and transition elements: Two new functionals and systematic testing of four M06-class functionals and 12 other functionals. Theor. Chem. Acc. 2008, 120, 215-241.

(48) Weigend, F.; Ahlrichs, R. Balanced basis sets of split valence, triple zeta valence and quadruple zeta valence quality for $\mathrm{H}$ to $\mathrm{Rn}$ : Design and assessment of accuracy. Phys. Chem. Chem. Phys. 2005, 7, 3297-3305.

(49) Tomasi, J.; Persico, M. Molecular interactions in solution: An overview of methods based on continuous distributions of the solvent. Chem. Rev. 1994, 94, 2027-2094. 